\title{
National Survey of Decision-Making for Antidepressants and Educational Level
}

\author{
Suzanne Brodney, PhD, RD, Floyd J. Fowler Jr, PhD, Vickie Stringfellow, BA, \\ K. D. Valentine, PhD, and Michael J. Barry, $M D$
}

Background: Despite recommendations to screen adults for depression in primary care, little is known about how people across education levels decide to treat their depression and factors that influence their decision.

Methods: We conducted a secondary analysis of a national, probability-based web survey in Englishspeaking adults aged 40 or older living in the United States who reported they discussed starting or continuing an antidepressant with their clinician in the past 2 years. Respondents answered questions about knowledge, decision-making process, and demographics. Education level was analyzed using 5 ordered categories. The Shared Decision Making (SDM) Process score was used to assess patient involvement. Descriptive statistics, $\chi^{2}$ tests, analysis of variance, and regression models were used to describe the data and test associations.

Results: Of the 5682 people invited, 3396 answered questions about health decisions $\mathbf{5 9 . 8 \%}$ response rate) and 385 reported discussing antidepressants. The mean percentage of knowledge questions answered correctly increased as education level increased $(P=.008)$. The mean SDM Process score also increased with education $(P=.001)$. There was an association between education and who made the treatment decision, suggesting that for respondents with less education, the clinician was more likely to decide $(P=.001)$. Respondents with less education were less likely to report they would definitely make the same decision again $(P=.000)$.

Conclusions: Those with less education were even less informed, had lower SDM Process scores and were less likely to think they made the right decision about antidepressants. There is a need to ensure patients are better informed about and involved in treatment for depression. ( $\mathrm{J}$ Am Board Fam Med 2020;33:80-90.)

Keywords: Antidepressants, Chi-Square Test, Clinical Decision-Making, Demography, Depression, Mental Health, Patient Participation, Patient Preference, Primary Health Care, Surveys and Questionnaires, Variance Analysis

The US Preventive Services Task Force recommends screening adults in the general population for depression, including older adults and pregnant

This article was externally peer reviewed.

Submitted 2 April 2019; revised 17 July 2019; accepted 19 July 2019.

From Division of General Internal Medicine, Massachusetts General Hospital, Boston (SB, KDV, MJB); Center for Survey Research, University of Massachusetts, Boston, (FJF).

Funding: SB and MJB are currently supported in part by a grant from Healthwise to Massachusetts General Hospital, which provided support for this analysis. The grant funding agreement ensured the authors' independence in designing this study, interpreting the data, writing, and publishing the report. The TRENDS survey was originally funded by the Informed Medical Decisions Foundation, prior to its 2014 merger with Healthwise, a nonprofit patient education and decision support organization based in Boise, Idaho. and postpartum women, concluding that screening is of moderate net benefit. However, screening should be implemented with adequate systems in place to ensure accurate diagnosis, effective treatment, and appropriate follow-up. ${ }^{1}$ Results from the 2015 National Survey on Drug Use and Health estimated that in the past year about 16.1 million adults had at least 1 major depressive episode. ${ }^{2}$ Mental disorders were listed as the costliest condition for institutionalized and noninstitutionalized populations. ${ }^{3}$ The majority of those seeking treat-

Conflict of interest: none.

Corresponding author: Suzanne Brodney, PhD, RD, Division of General Internal Medicine, Massachusetts General Hospital, 100 Cambridge Street, $16^{\text {th }}$ Floor, Boston, MA 02114 (E-mail: sbrodney@mgh.harvard.edu). 
ment for depression do so in primary care, ${ }^{4}$ although the most effective interventions to increase depression treatment initiation in primary care are unclear. $^{5}$

Once a patient is screened for depression and identified as requiring follow-up, patients and providers have a variety of pharmacologic and nonpharmacologic treatment choices to consider. ${ }^{6-8}$ The practice guideline from the American College of Physicians recommends cognitive behavioral therapy or a second-generation antidepressant after discussing the options with the patient and incorporating the patients' preferences. ${ }^{6}$ Despite the available options, less than one-third of people identified as depressed receive treatment.9 Many cases of screen-detected depression will be at the milder end of a severity spectrum within Major Depressive Disorder. For these individuals, the efficacy of antidepressant treatment seems limited. ${ }^{10}$ A recent commentary offers suggestions for helping physicians in primary care settings address depression treatment options and uncertainties. ${ }^{11}$

There is limited evidence on how involved people are with the decision to treat their depression and the factors that influence whether or not the decision aligns with the patients' values and preferences. Results from a meta-analysis of patient preferences for psychiatric disorders reported that overwhelmingly patients prefer psychological treatment compared with pharmacologic treatment. ${ }^{12}$ Hines and colleagues ${ }^{13}$ compared audiotapes of postvisit surveys from patients and their clinicians. They found that only $9 \%$ of depression-related treatment decisions met the basic elements of informed decision making.

Shared decision making (SDM) has been identified as an approach to help patients and clinicians with the decision to treat depression. SDM, which is a communication process by which patients work with clinicians to make better health decisions, has 3 core components: (1) clear, accurate, and unbiased medical evidence about the reasonable alternatives, including no intervention, and the risks and benefits of each option; (2) expertise in communicating and personalizing that evidence to the individual patient; and (3) patients' goals, concerns, and informed preferences. ${ }^{14} \mathrm{SDM}$ has been reported to be better than usual care as a method to improve decision making for depression treatment, ${ }^{15-17}$ but survey data exploring to what extent SDM occurs in primary care for depression indicate SDM is underutilized. ${ }^{18-20}$

Making a high-quality treatment decision includes understanding basic facts about the condition and treatment choices. Cross-sectional studies of adults show that on average patients are poorly informed and not very involved in their treatment decisions. ${ }^{21-23}$ People with less formal education have significantly less knowledge about their options than others. ${ }^{24}$ In a medically underserved population, patients with lower health literacy were less likely to engage in decision making. ${ }^{25}$

The purpose of this analysis was to explore the association between depression treatment, education level, and the patient role in the treatment decision, in terms of being informed and involved. We hypothesized that respondents with less education would be less informed about their condition and treatment options, less involved in the decision-making process, and experience more dissonance between their preferred and the actual treatment decision compared with those with more education.

\section{Methods}

\section{Study Population and Data}

The data for this secondary analysis were collected as part of the TRENDS survey, which was conducted between November and December 2011 by Knowledge Networks using a probability-based web panel designed to be representative of adults aged 40 and older living in US households. This is a secondary analysis of individuals who responded that they engaged in a decision about depression treatment. The methodology has been previously published. ${ }^{26}$ This survey only included people who could respond in English. The survey was reviewed and approved by New England Independent Review Board.

Briefly, Knowledge Networks sampled households from its KnowledgePanel to represent a cross-section of adults 40 or older in the United States. Both random-digit dialing and addressbased sampling were used to recruit the original panel. People who were recruited but did not have computers or Internet service were provided with both so that the samples did not exclude those who lacked Internet access. Once the respondents were invited to participate, they answered a set of questions to identify those who had experienced or had had discussion with a medical provider regarding at least 1 of 10 decisions in the past 2 years. These 
included being screened for colorectal, breast, or prostate cancer; starting or stopping medication for hypertension, high cholesterol, or depression; having a knee or hip replacement for osteoarthritis; or having surgery for cataracts or low back pain. Those not meeting the criteria were excluded from further participation. Those who were eligible continued with the main survey. When respondents reported being eligible for the survey based on more than 1 topic, a probability selection was made of 2 topics to address in the survey, with the less common decisions being given a higher probability of selection. This analysis focuses on the 385 respondents who completed the depression survey after reporting a discussion with a health care provider in the past 2 years about starting or continuing antidepressant medication.

\section{Main Measures}

The survey gathered data on demographic characteristics, including age, sex, race, education, marital status, work status, household income, health insurance status, and self-reported health. Education was stratified into 5 categories: less than high school graduate, high school graduate, some college, college graduate, and graduate work. Scales were included to determine to what extent respondents were informed and involved and would make the same decision about antidepressant treatment again.

\section{Informed \\ To explore how informed respondents were about their depression treatment options, they were asked 5 knowledge questions (4 multiple choice and 1 fill in the blank). A score for each respondent was calculated based on the percentage answered cor- rectly. The questions were developed by an expe- rienced depression researcher and psychometri- cians to cover what they considered the most essential facts needed in order make an informed treatment decision. These questions were first used as part of the DECISIONS study ${ }^{26}$ conducted by the Univer- sity of Michigan in 2008 and were reviewed for cur- rency in 2011. All questions were cognitively tested to make sure they were consistently understood. Knowl- edge questions that were not answered were consid- ered incorrect. (Appendix)}

\section{Involved}

An SDM Process score was calculated based on responses to 4 questions about how much the pros and cons of the decision were discussed, if the choices were explained, and if the provider asked what the respondent wanted to do. The score is based on questions first used in the DECISIONS study $^{27}$ and have been used in several subsequent studies. ${ }^{28}$ The SDM Process score has been endorsed as a quality measure by the National Quality Forum (NQF) (http://www.qualityforum.org/QPS/ QPSTool.aspx). A higher score indicates more involvement in the decision. For the NQF measure, a score of 3 (range, 0 to 4 ) or better has been considered "good." One point each was assigned for discussing the pros and cons "a lot" or "some" and responding "yes" if the provider explained the choices and "yes" if the provider asked the respondent what treatment they wanted. Respondents were also asked who made the final decision about taking medication (the patient, the provider, or the decision was made together).

\section{Make the Same Decision Again}

To evaluate if respondents were comfortable with their actual treatment, they were asked if they would make the same decision about starting or stopping antidepressants again (definitely yes, probably yes, probably no, or definitely no).

\section{Data Analysis}

The survey results were designed to be representative of US English-speaking adults aged 40 and older who discussed starting or continuing medication for depression within 2 years of the survey. All results were weighted to adjust for differences in the probability of selection due to the number of decisions reported. Analyses were conducted using IBM SPSS Complex Samples Module, version 21, and $\mathrm{R}$ version 3.5.2. ${ }^{29}$

The primary focus of the analysis was how knowledge and the decision-making process differed by the level of formal education reported by the respondent. Means and standard deviations were calculated for continuous variables, and frequencies were calculated for categorical variables. $\chi^{2}$ analyses were conducted to explore the relationship between education level and categorical variables, including demographics, decision process, and comfort with the decision. Knowledge was assessed by examining the mean percent correct 
Table 1. Characteristics of Respondents Considering Starting or Stopping Antidepressants by Educational Level

\begin{tabular}{|c|c|c|c|c|c|c|}
\hline \multirow[b]{2}{*}{ Characteristic } & \multicolumn{5}{|c|}{ Education Level } & \multirow[b]{2}{*}{$\begin{array}{c}\chi^{2} \\
P \text { Value }\end{array}$} \\
\hline & $\begin{array}{l}\text { Less Than High } \\
\text { School }(\mathrm{N}=55)\end{array}$ & $\begin{array}{l}\text { High School Grad } \\
\qquad(\mathrm{N}=118)\end{array}$ & $\begin{array}{l}\text { Some College } \\
\quad(\mathrm{N}=116)\end{array}$ & $\begin{array}{l}\text { College Grad } \\
(\mathrm{N}=55)\end{array}$ & $\begin{array}{l}\text { Graduate Work } \\
\quad(\mathrm{N}=41)\end{array}$ & \\
\hline \multicolumn{7}{|l|}{ Age, years (\%) } \\
\hline$<60$ & 68 & 59 & 68 & 69 & 66 & \multirow[t]{3}{*}{.186} \\
\hline 60 to 74 & 17 & 30 & 27 & 26 & 19 & \\
\hline $75+$ & 14 & 11 & 5 & 4 & 15 & \\
\hline \multicolumn{7}{|l|}{ Sex $(\%)$} \\
\hline Female & 69 & 68 & 65 & 72 & 71 & .088 \\
\hline \multicolumn{7}{|l|}{ Race (\%) } \\
\hline White, non-Hispanic & 74 & 80 & 72 & 75 & 88 & \multirow[t]{3}{*}{.032} \\
\hline Black, non-Hispanic & 19 & 6 & 9 & 6 & 1 & \\
\hline Other & 7 & 14 & 19 & 19 & 11 & \\
\hline \multicolumn{7}{|l|}{ Marital status (\%) } \\
\hline Married/living with partner & 53 & 60 & 54 & 58 & 55 & \multirow[t]{2}{*}{.906} \\
\hline Not married/living with partner & 47 & 40 & 46 & 42 & 45 & \\
\hline \multicolumn{7}{|l|}{ Work status (\%) } \\
\hline Working & 15 & 26 & 52 & 50 & 71 & \multirow[t]{3}{*}{.000} \\
\hline Not working (not retired) & 63 & 45 & 30 & 25 & 8 & \\
\hline Retired & 22 & 29 & 19 & 25 & 21 & \\
\hline \multicolumn{7}{|l|}{ Household income (\%) } \\
\hline$<\$ 50,000$ & 82 & 75 & 56 & 40 & 24 & \multirow[t]{3}{*}{.000} \\
\hline$\$ 50,000-\$ 99,999$ & 13 & 21 & 27 & 26 & 28 & \\
\hline$\$ 100,000$ or more & 5 & 4 & 17 & 34 & 48 & \\
\hline \multicolumn{7}{|l|}{ Health insurance (\%) } \\
\hline Yes & 88 & 88 & 85 & 92 & 97 & \multirow[t]{2}{*}{.241} \\
\hline No & 12 & 12 & 15 & 8 & 3 & \\
\hline \multicolumn{7}{|l|}{ Self-reported health (\%) } \\
\hline Excellent & 8 & 2 & 1 & 16 & 5 & \multirow[t]{5}{*}{.000} \\
\hline Very good & 6 & 14 & 23 & 26 & 46 & \\
\hline Good & 17 & 52 & 44 & 39 & 31 & \\
\hline Fair & 56 & 23 & 25 & 19 & 17 & \\
\hline Poor & 13 & 9 & 8 & 0 & 1 & \\
\hline
\end{tabular}

based on the 5 knowledge questions. Analysis of variance was used to assess differences across education levels for the mean percent correct knowledge answers and the mean SDM Process scores. A simultaneous linear regression model was conducted to explore the relationship between education level and SDM Process score when adjusting for age, sex, ethnicity, income, health status, and insurance status. When data were checked for outliers, 1 outlying observation was identified, but results did not change with or without this observation, so it was allowed to remain in the dataset. All other assumptions were met for the model.

\section{Results}

Of the 5682 panel members asked to participate in the national survey, 3396 (59.6\%) answered the screening question whether they had discussed a decision with a health care professional. Of these members, 2788 reported making 1 or more decisions and 2718 then completed the survey $(97.5 \%$ of those eligible). The overall response rate of $58.3 \%$ assumes nonrespondents were eligible at the same rate as screening question respondents. A total of 385 respondents who reported a discussion about antidepressant medication with their provider are included in this analysis.

\section{Demographics}

Table 1 describes the characteristics of the respondents who made a decision about antidepressant medication. About two-thirds of the sample was less than 60 years of age, and a similar percentage was female. Age and sex did not differ significantly 
Figure 1. Mean percent of knowledge questions answered correctly.

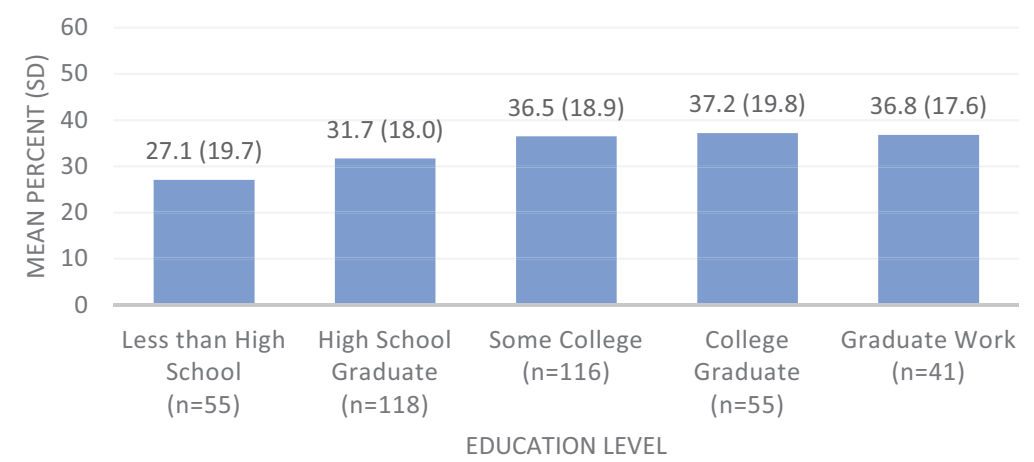

across education levels. The majority of participants in each education level were non-Hispanic white. Education was directly and significantly related to the likelihood of being employed, and there was a strong monotonic relationship between education and family income. There was no difference in the percentages with health insurance across education levels, Although those with less education reported lower health status than those with more education.

\section{Informed}

Across education categories, respondents were poorly informed about the key facts of depression treatment (Figure 1). Regardless of education, the mean percentage of questions respondents answered correctly was well less than $50 \%$. Only 16 of the 385 respondents answered 4 or more of the 5 questions correctly (data not shown). Across all respondents, the mean percent of knowledge questions answered correctly was significantly related to education $(\mathrm{F}=3.47, P=.008)$.

\section{Involved}

The mean SDM Process score differed significantly across education levels $(\mathrm{F}=4.92, P=.001)$; mean scores rose monotonically from the lowest education group to the highest from 2.26 up to 3.22 on the 4-point scale (Table 2). For the top 2 education strata, the mean SDM Process score was in the "good" range based on the scoring as an NQF measure. When the components of the score were explored individually, there were significant differences in how much respondents reported that providers discussed the cons of taking antidepressants ( $41 \%$ of respondents in the lowest education level reported "not at all" compared with $10 \%$ of re- spondents in the highest). Similarly, for those in the lowest education level, $25 \%$ reported that the provider did not explain the choices compared with $17 \%$ in the highest. When asked if the provider asked them whether or not they wanted to start or continue taking an antidepressant, $57 \%$ of those in the lowest education level reported that they were not asked compared with $24 \%$ in the highest level. Furthermore, when entered into a linear model, having more education was found to be related to higher SDM Process scores $(b=0.13, P<.001)$ when adjusting for other demographic variables, including race and ethnicity.

Consistent with those results, the more formal education respondents had, the more likely they were to say that they mainly made the decision about an antidepressant themselves (59\% vs $35 \%$ ), whereas those with less formal education were more likely to say their providers mainly made the decision (27\% vs $2 \%)$.

\section{Make the Same Decision Again}

Finally, when asked if they would make the same decision again about antidepressants, there was a clear relationship indicating that the higher the respondents' education, the more likely they were to say that they would "definitely" make the same decision again $(70 \%$ in the highest education level vs $53 \%$ in the lowest education level, $P<.000$ ). Compared with those with the highest education level, those in the lowest education level were more likely to report they would "definitely not" make the same decision again (15\% vs $3 \%)$.

\section{Discussion}

Our hypotheses were that people with less formal education who had made a decision about starting 
Table 2. Level of Involvement in the Antidepressant Decision by Education

\begin{tabular}{|c|c|c|c|c|c|c|}
\hline \multirow[b]{2}{*}{ Decision Process } & \multicolumn{5}{|c|}{ Education Level } & \multirow[b]{2}{*}{$P$ Value } \\
\hline & $\begin{array}{l}\text { Less than High School } \\
\qquad(\mathrm{N}=55)\end{array}$ & $\begin{array}{l}\text { High School Grad } \\
\qquad(\mathrm{N}=118)\end{array}$ & $\begin{array}{l}\text { Some College } \\
\quad(\mathrm{N}=116)\end{array}$ & $\begin{array}{l}\text { College Grad } \\
\quad(\mathrm{N}=55)\end{array}$ & $\begin{array}{l}\text { Graduate Work } \\
\quad(\mathrm{N}=41)\end{array}$ & \\
\hline \multicolumn{7}{|c|}{ SDM Process score, mean (SD) } \\
\hline & $2.26(1.3)$ & $2.60(1.2)$ & $2.64(1.2)$ & $3.04(1.0)$ & $3.22(1.2)$ & $.001^{*}$ \\
\hline \multicolumn{7}{|l|}{ Discussed pros (\%) } \\
\hline Not at all & 9 & 4 & 5 & 4 & 2 & $.271^{\dagger}$ \\
\hline A little & 20 & 12 & 15 & 13 & 7 & \\
\hline Some & 22 & 38 & 40 & 35 & 27 & \\
\hline A lot & 49 & 47 & 41 & 49 & 63 & \\
\hline \multicolumn{7}{|l|}{ Discussed cons (\%) } \\
\hline Not at all & 41 & 40 & 32 & 13 & 10 & $.000^{\dagger}$ \\
\hline A little & 18 & 20 & 27 & 28 & 15 & \\
\hline Some & 18 & 28 & 26 & 33 & 61 & \\
\hline A lot & 23 & 12 & 15 & 26 & 13 & \\
\hline \multicolumn{7}{|c|}{ Explained choices (\%) } \\
\hline Yes & 75 & 67 & 80 & 87 & 83 & $.022^{\dagger}$ \\
\hline No & 25 & 33 & 20 & 13 & 17 & \\
\hline \multicolumn{7}{|c|}{ Provider asked tou (\%) } \\
\hline Yes & 43 & 70 & 65 & 74 & 76 & $.004^{\dagger}$ \\
\hline No & 57 & 31 & 35 & 26 & 24 & \\
\hline \multicolumn{7}{|c|}{ Who made the final decision (\%) } \\
\hline Mainly patient & 35 & 36 & 48 & 44 & 59 & $.001^{\dagger}$ \\
\hline Made together & 38 & 51 & 43 & 52 & 39 & \\
\hline Mainly provider & 27 & 13 & 9 & 4 & 2 & \\
\hline \multicolumn{7}{|c|}{ Would you make the same decision again (\%) } \\
\hline Definitely yes & 53 & 53 & 52 & 63 & 70 & $.000^{\dagger}$ \\
\hline Probably yes & 33 & 31 & 42 & 33 & 23 & \\
\hline Probably no & 0 & 13 & 4 & 2 & 5 & \\
\hline Definitely no & 15 & 3 & 2 & 2 & 3 & \\
\hline
\end{tabular}

*Analysis of variance used to test difference in means across education level.

${ }^{\dagger} \chi^{2}$ test used to test for difference across categorical variables.

or stopping antidepressants would be less informed, less involved, and less likely to report they would make the same decision again. Regardless of educational level, respondents were not well informed about their condition and treatment options, and those with less education were even less informed. Compared with those with higher education, those with less education were also less involved in the decision to start or continue taking antidepressant medication, more often reported the provider made the final decision, and less likely to report they would make the same decision again. After adjusting for other demographic factors, including race and ethnicity, the significant relationship between SDM Process and education level remained.

Prior national surveys of medical decision making indicate that people often do not know basic facts about common medical decisions they have made. $^{23,24}$ A recent review of decision making needs in patients with depression and schizophrenia reported that patients have an unmet need for information about basic facts, treatment, and coping, as well as decisions about medication and treatment setting. ${ }^{30}$ Patients and clinicians also have different perceptions of what is most important for patients to know about their treatment. ${ }^{19}$ Having an objective measure of facts about a decision is crucial to making an informed decision. The knowledge questions used in this survey may be imperfect, but they represent one reasonable and thoughtful effort to define the information needed to make an informed decision.

Across a range of treatment and screening decisions, patients are often not optimally included. ${ }^{22,23,26,31}$ Similar to other medical decisions, respondents reported that clinicians discussed the 
pros of antidepressant treatment more than the cons. ${ }^{27}$ In this analysis, for those with less formal education, the cons of the decision were discussed less often compared with those with more education. For example, $41 \%$ in the lowest education level reported no discussion of cons at all, compared with $10 \%$ in the highest education category. In addition, the less educated the patient, the less participation in the decision they reported. Lower educated respondents reported that clinicians included them in the decision about half as often as higher educated patients ( $43 \%$ vs $76 \%$ ). The survey was conducted in 2011. Since that time, SDM may have improved such that our data do not reflect what is actually happening in clinics now. However, we are not aware of any data documenting such an improvement.

Increasing patient engagement by offering educational information that is accessible to all should help to minimize the gap observed by those with education levels. In 2015 Wexler and colleagues ${ }^{32}$ published a manuscript describing patient responses to decision aids in the United States. Participants were 3001 patients from 6 primary care sites across the United States who were facing 1 of 16 common medical decisions. In this sample, which included $33 \%$ of patients with a high school education or less, giving patients decision aids resulted in patients achieving knowledge scores at least as high as those who had obtained a higher level of education.

Importantly, a lack of involvement in the treatment decision may impact adherence to antidepressant medication once it is prescribed. ${ }^{33}$ Jaffray and colleagues $^{34}$ conducted a qualitative study with patients recently started on antidepressants looking at why patients discontinued their treatment. Ownership, knowledge, and support were found to be the main factors impacting why patients adhere to treatment and that joint decision making was associated with more positive attitudes toward antidepressant use. These data show that because of the way physicians and patients interact, those with less education are likely to be disadvantaged with respect to commitment and ownership of the decision to take antidepressants.

With increasingly widespread screening for depression in primary care, driven in part by clinical practice guidelines, it is important to ensure subsequent decisions about treatment, particularly for screen-detected cases, are of high quality. The re- sults of this study suggest substantial room for improvement in helping all patients, but more specifically those with less formal education, to understand what a diagnosis of depression means, the pros and cons of the treatment options, and how to incorporate the patient's treatment preference. One method to improve communication is to offer patients certified patient decision aids, which have been proven to improve outcomes. ${ }^{35}$ In populations where there is a disparity in who receives treatment, patient decision aids have helped align the patient's treatment preference to the treatment received. ${ }^{36,37}$

Identifying and/or creating patient decision aids that meet certification criteria, addressing the decisions relevant to what patients are faced with, and ensuring the tools are accessible to people with lower education levels are all necessary. Clinicians should also be trained in how to engage in SDM to ensure that patients educated about SDM do not encounter a system that is not willing to include them in the process. System changes are also necessary to optimize how and when patients receive decision support materials.

There are limitations to our analysis. The data, which were collected in 2011, may now differ because of the increased focus on depression awareness, screening, and treatment, although it seems unlikely that the patterns of interaction between patients and physicians we describe have fundamentally changed. The survey only included English-speaking adults, but one would hypothesize that these issues may be even more problematic for those who do not speak English. The content of the conversations between patients and physicians was not recorded, so these data are based on patient reports about their knowledge and interactions that occurred, on average, a year before the interview. It is possible that the 2-year recall period could have impacted respondents' answers; however, a recent analysis by Sepucha and colleagues ${ }^{38}$ found that timing of measurement on decision quality and SDM did not show a difference in mean knowledge scores between 1 month and 1 year. We also acknowledge the possibility of nonresponse bias from the original sample, which would impact the generalizability of our findings. The sample from Knowledge Networks should be representative, but because respondents self-selected into the study panel, there is a possibility that those who were invited but did not self-select are different from 
those who were invited to the panel and agreed to participate.

\section{Conclusion}

The majority of respondents were poorly informed about their treatment options for depression. Those with less education were even less informed, had lower SDM Process scores, were more likely to think the doctor made the decision, and were less likely to think they made the right decision. As more patients are identified through screening, there is a need to ensure patients are better informed about and involved in treatment for depression.

This work was presented as a poster at the Society for Medical Decision Making annual meeting in October 2017 in Pittsburgh, PA.

Dr. Barry is a member of the United States Preventive Services Task Force (USPSTF). This article does not necessarily represent the views and policies of the USPSTF.

To see this article online, please go to: http://jabfm.org/content/ 33/1/80.full.

\section{References}

1. Siu AL, Bibbins-Domingo K, Grossman DC, et al. Screening for depression in adults: US Preventive Services Task Force recommendation statement. JAMA 2016;315:380-7.

2. Bose J, Hedden SL, Lipari RN, Park-Lee E. Key Substance Use and Mental Health Indicators in the United States: Results from the 2015 National Survey on Drug Use and Health. HHS Publication No. SMA 16-4984, NSDUH Series H-51. Rockville, MD: Substance Abuse and Mental Health Services Administration; 2016.

3. Roehrig C. Mental disorders top the list of the most costly conditions in the United States: \$201 billion. Health Aff (Project Hope) 2016;35:1130-5.

4. Petterson S, Miller BF, Payne-Murphy JC, Phillips RL. Mental health treatment in the primary care setting: patterns and pathways. Fam Syst Health 2014;32:157-66.

5. Moise N, Falzon L, Obi M, et al. Interventions to increase depression treatment initiation in primary care patients: a systematic review. J Gen Intern Med 2018;33:1978-89.

6. Qaseem A, Barry MJ, Kansagara D. Nonpharmacologic versus pharmacologic treatment of adult patients with major depressive disorder: a clinical practice guideline from the American College of Physicians. Ann Intern Med 2016;164:350-9.

7. Farah WH, Alsawas M, Mainou M, et al. Nonpharmacological treatment of depression: a system- atic review and evidence map. Evid Based Med 2016; 21:214-21.

8. Cipriani A, Furukawa TA, Salanti G, et al. Comparative efficacy and acceptability of 21 antidepressant drugs for the acute treatment of adults with major depressive disorder: a systematic review and network meta-analysis. Lancet 2018;391:1357-66.

9. Olfson M, Blanco C, Marcus SC. Treatment of adult depression in the United States. JAMA Intern Med 2016;176:1482-91.

10. Fournier JC, DeRubeis RJ, Hollon SD, et al. Antidepressant drug effects and depression severity: a patient-level meta-analysis. JAMA 2010;303:47-53.

11. Cosgrove L, Erlich D, Shaughnessy AF. No Magic pill: a prescription for enhanced shared decisionmaking for depression treatment. J Am Board Fam Med 2019;32:6-9.

12. McHugh RK, Whitton SW, Peckham AD, Welge JA, Otto MW. Patient preference for psychological vs pharmacologic treatment of psychiatric disorders: a meta-analytic review. J Clin Psych 2013;74:595602.

13. Hines AL, Roter D, Ghods Dinoso BK, Carson KA, Daumit GL, Cooper LA. Informed and patient-centered decision-making in the primary care visits of African Americans with depression. Patient Educ Couns 2018;101:233-40.

14. Patient-Centered Primary Care Collaborative. Shared Decision Making: A Standard of Care for All Patients. Washington, DC: National Quality Forum; 2017:4.

15. LeBlanc A, Herrin J, Williams MD, et al. Shared decision making for antidepressants in primary care: a cluster randomized trial. JAMA Intern Med 2015; 175:1761-70.

16. Perestelo-Perez L, Rivero-Santana A, SanchezAfonso JA, et al. Effectiveness of a decision aid for patients with depression: a randomized controlled trial. Health Expect 2017;20:1096-105.

17. Loh A, Simon D, Wills CE, Kriston L, Niebling W, Harter M. The effects of a shared decision-making intervention in primary care of depression: a clusterrandomized controlled trial. Patient Educ Couns 2007;67:324-32.

18. Saver BG, Van-Nguyen V, Keppel G, Doescher MP. A qualitative study of depression in primary care: missed opportunities for diagnosis and education. J Am Board Fam Med 2007;20:28-35.

19. Barr PJ, Forcino RC, Mishra M, Blitzer R, Elwyn G. Competing priorities in treatment decision-making: a US national survey of individuals with depression and clinicians who treat depression. BMJ Open 2016;6:e009585.

20. Solberg LI, Crain AL, Rubenstein L, Unutzer J, Whitebird RR, Beck A. How much shared decision making occurs in usual primary care of depression? J Am Board Fam Med 2014;27:199-208.

21. Fowler FJ, Jr., Gallagher PM, Bynum JP, Barry MJ, Lucas FL, Skinner JS. Decision-making process re- 
ported by Medicare patients who had coronary artery stenting or surgery for prostate cancer. J Gen Intern Med 2012;27:911-6.

22. Hoffman RM, Elmore JG, Fairfield KM, Gerstein BS, Levin CA, Pignone MP. Lack of shared decision making in cancer screening discussions: results from a national survey. Am J Prev Med 2014;47:251-9.

23. Hoffman RM, Elmore JG, Pignone MP, Gerstein BS, Levin CA, Fairfield KM. Knowledge and values for cancer screening decisions: Results from a national survey. Patient Educ Couns 2016;99:624-30.

24. Fagerlin A, Sepucha KR, Couper MP, Levin CA, Singer E, Zikmund-Fisher BJ. Patients' knowledge about 9 common health conditions: the DECISIONS survey. Med Decis Making 2010;30:52S.

25. Seo J, Goodman MS, Politi M, Blanchard M, Kaphingst KA. Effect of health literacy on decision-making preferences among medically underserved patients. Med Decis Making 2016;36:550-6.

26. Fowler FJ Jr, Gerstein BS, Barry MJ. How patient centered are medical decisions?: Results of a national survey. JAMA Intern Med 2013;173:1215-1221.

27. Zikmund-Fisher BJ, Couper MP, Singer E, et al. The DECISIONS study: a nationwide survey of United States adults regarding 9 common medical decisions. Med Decis Making 2010;30:20s-34s.

28. Sepucha K, Atlas SJ, Chang Y, et al. Patient decision aids improve decision quality and patient experience and reduce surgical rates in routine orthopaedic care: a prospective cohort study. J Bone Joint Surg Am 2017;99:1253-60.

29. R: A language and environment for statistical computing. R Foundation for Statistical Computing 2018; https://www.R-project.org/.

30. Tlach L, Wusten C, Daubmann A, Liebherz S, Harter M, Dirmaier J. Information and decision-making needs among people with mental disorders: a systematic review of the literature. Health Expect 2015; 18:1856-72.

31. Fairfield KM, Gerstein BS, Levin CA, Stringfellow $\mathrm{V}$, Wierman HR, McNaughton-Collins M. Decisions about medication use and cancer screening across age groups in the United States. Patient Educ Couns 2015;98:338-43.

32. Wexler RM, Gerstein BS, Brackett C, et al. Patient responses to decision aids in the United States. Int. J Person Center Med 2015;5:105-111.
33. Bauer AM, Parker MM, Schillinger D, et al. Associations between antidepressant adherence and shared decision-making, patient-provider trust, and communication among adults with diabetes: diabetes study of Northern California (DISTANCE). J Gen Intern Med 2014;29:1139-47.

34. Jaffray M, Cardy AH, Reid IC, Cameron IM. Why do patients discontinue antidepressant therapy early? A qualitative study. Eur J Gen Pract 2014;20:167-73.

35. Stacey D, Legare F, Lewis, et al. Decision aids for people facing health treatment or screening decisions. Cochrane Database Syst Rev. 2017;4: CD001431.

36. Ibrahim SA, Blum M, Lee GC, et al. Effect of a decision aid on access to total knee replacement for black patients with osteoarthritis of the knee: a randomized clinical trial. JAMA Surg 2017;152:e164225.

37. Durand MA, Carpenter L, Dolan H, et al. Do interventions designed to support shared decision-making reduce health inequalities? A systematic review and meta-analysis. PLoS One 2014;9:e94670.

38. Sepucha KR LA, Belkora J, Chang Y, Moy B, Partridge A, Lee CN. Impact of timing on measurement of decision quality and shared decision making: longitudinal cohort study of breast cancer patients. Med Decis Making 2019;39:642-650.

39. Mulrow CD, Williams JW, Chiquette E, et al. Efficacy of newer medications for treating depression in primary care patients. Am J Med 2000;108:54-64.

40. Churchill R, Hunot V, Corney R, et al. A systematic review of controlled trials of the effectiveness and costeffectiveness of brief psychological treatments for depression. Health Technol Assess 2001;5:1-173.

41. Pignone MP, Gaynes BN, Rushton JL, et al. Screening for depression in adults: a summary of the evidence for the U.S. Preventive Services Task Force. Ann Intern Med 2002;136:765-76.

42. de Jonghe F, Kool S, van Aalst G, Dekker J, Peen J. Combining psychotherapy and antidepressants in the treatment of depression. J Affect Disorder 2001; 64:217-229.

43. Pampallona S, Bollini P, Tibaldi G, Kupelnick B, Munizza C. Combined pharmacotherapy and psychological treatment for depression: a systematic review. Arch Gen Psych 2004;61:714-9.

44. Nieuwsma JA, Trivedi RB, McDuffie J, Kronish I, Benjamin D, Williams JW. Brief psychotherapy for depression: a systematic review and meta-analysis. Int J Psych Med 2012;43:129-51. 
Appendix. Survey Questions

\begin{tabular}{|c|c|}
\hline Survey Instrument & Questions \\
\hline $\begin{array}{l}\text { Shared Decision Making } \\
\text { Process Scale }\end{array}$ & $\begin{array}{l}\text { How much did you and the health care provider discuss with you the reasons to [continue } \\
\text { taking/take] antidepressant medication? } \\
\text { o A lot } \\
\text { o Some } \\
\text { o A little } \\
\text { o Not at all }\end{array}$ \\
\hline $\begin{array}{l}\text { Shared Decision Making } \\
\text { Process Scale }\end{array}$ & $\begin{array}{l}\text { How much did you and the health care provider discuss with you the reasons not to } \\
\text { [continue taking/take] antidepressant medication? } \\
\text { o A lot } \\
\text { o Some } \\
\text { o A little } \\
\text { o Not at all }\end{array}$ \\
\hline $\begin{array}{l}\text { Shared Decision Making } \\
\text { Process Scale }\end{array}$ & $\begin{array}{l}\text { Did the health care provider explain there were choices in what you could do to treat } \\
\text { your depression? } \\
\text { o Yes } \\
\text { o No }\end{array}$ \\
\hline $\begin{array}{l}\text { Shared Decision Making } \\
\text { Process Scale }\end{array}$ & $\begin{array}{l}\text { Did the health care provider ask you whether or not you wanted to [continue taking/take] } \\
\text { antidepressant medication at the time? } \\
\text { o Yes } \\
\text { o No }\end{array}$ \\
\hline Knowledge & $\begin{array}{l}\text { Out of } 100 \text { people who have been told they have mild to moderate depression and who } \\
\text { do not do anything to treat it, about how many will feel better within a year? } \\
\text { Range } 0-100 \\
\text { Correct answer }{ }^{39} \text { : Between } 25 \text { to } 49\end{array}$ \\
\hline Knowledge & $\begin{array}{l}\text { If a person starts feeling better after taking antidepressant medicine, when should he or } \\
\text { she talk with the doctor about stopping the medicine? } \\
\text { o As soon as the person feels better } \\
\text { o } 6 \text { to } 12 \text { months after feeling better } \\
\text { o A person should never stop taking the medication } \\
\text { Correct answer }{ }^{10,40}: 6 \text { to } 12 \text { months after feeling better }\end{array}$ \\
\hline Knowledge & $\begin{array}{l}\text { For most people who have been told they have mild to moderate depression, which } \\
\text { treatment is more effective? } \\
\text { o Antidepressant medication } \\
\text { o Depression counseling or therapy } \\
\text { o There is little or no difference } \\
\text { Correct answer }{ }^{10,40,41} \text { : There is little or no difference }\end{array}$ \\
\hline Knowledge & $\begin{array}{l}\text { For most people who have been told they have severe depression, which treatment is } \\
\text { more effective? } \\
\text { o Antidepressant medication } \\
\text { o Depression counseling or therapy } \\
\text { o A combination of medication and counseling or therapy } \\
\text { Correct answer }{ }^{10,42,43} \text { : A combination of medication and counseling or therapy }\end{array}$ \\
\hline Knowledge & $\begin{array}{l}\text { How long does a person usually need to get depression counseling to reduce symptoms of } \\
\text { depression? } \\
\text { o Less than } 6 \text { months } \\
\text { o } 6 \text { to } 12 \text { months } \\
\text { o } 1 \text { to } 2 \text { years } \\
\text { o More than } 2 \text { years } \\
\text { Correct answer: }{ }^{40,44} \text { Less than } 6 \text { months }\end{array}$ \\
\hline
\end{tabular}

Continued 
Appendix. Continued

Survey Instrument

Questions

Who made the decision?

Who made the final decision whether or not to [take/continue taking] antidepressant medicine?

o Mainly my decision

o Mainly the health care [providers'/provider's] decision

o We made the decision together

Make the same decision

If you knew then what you know now, do you think you would make the same decision again?

o Definitely yes

o Probably yes

o Probably no

o Definitely no 